\title{
Recent Shift in the State of the Western Pacific Subtropical High due to ENSO Change
}

\author{
ZongCi HuAng, Wenjun Zhang, AND Xin Geng \\ Collaborative Innovation Center on Forecast and Evaluation of Meteorological Disasters (CIC-FEMD)/Joint International Research \\ Laboratory of Climate and Environment Change (ILCEC), Key Laboratory of Meteorological Disaster of Ministry of Education, \\ Nanjing University of Information Science and Technology, Nanjing, China
}

FEI-FEI JIN

Department of Atmospheric Sciences, School of Ocean and Earth Science and Technology, University of Hawai'i at Mānoa, Honolulu, Hawaii

(Manuscript received 19 December 2018, in final form 10 September 2019)

\begin{abstract}
The boreal summer western Pacific subtropical high (WPSH) exhibits a remarkable decadal shift in its spatial pattern and periodicity around the late 1990s. In the former period, the WPSH is primarily characterized by a large-scale uniform pattern over Asia and its surrounding area with an oscillating period of $\sim 4-5$ yr. However, the WPSH-related atmospheric circulations shift to a dipole structure and oscillate at $\sim 2-3 \mathrm{yr}$ in the recent period. We found that this decadal shift is largely contributed by the ENSO regime change. During the former period, the tropical Pacific was dominated by the conventional eastern Pacific (EP) El Niño-Southern Oscillation (ENSO) with an oscillating period of $\sim 4-5 \mathrm{yr}$. Strong anticyclone anomalies usually are maintained over the western North Pacific (WNP) during the EP El Niño decaying summer, accounting for most of the WPSH temporal and spatial variability. In contrast, the recent period features much more frequent occurrence of central Pacific (CP) El Niño events in the tropical Pacific with a 2-3-yr oscillating period. A dipole structure in the WNP and Indian Ocean is evident during both developing and decaying summers of CP El Niño, consistent with the WPSH leading mode after the late 1990s. The results have important implications for seasonal prediction of the WPSH and associated Asian summer climate anomalies.
\end{abstract}

\section{Introduction}

The western Pacific subtropical high (WPSH) is an important circulation system over the subtropical western North Pacific (WNP) and adjacent lands. As a crucial component of East Asian summer monsoon circulation system, the WPSH exhibits remarkable interannual and decadal variability in terms of its intensity, structure, and zonal and meridional displacements (e.g., Tao and $\mathrm{Xu}$ 1962; Huang 1963; Lau and Li 1984; Tao and Chen 1987; Ding 1994; Zhao and Chen 1995). Possible mechanisms for the multiple time scale variability of the WPSH have drawn widespread attention due to pronounced climate implications over East Asia (e.g., Tao and Chen 1987; Sui et al. 2007; Chung et al. 2011; Xu et al. 2015; Wang et al. 2017), and so far the variability is not fully understood.

Due to the active regional ocean-atmosphere interaction, the underlying warm pool is intimately

\footnotetext{
Corresponding author: Wenjun Zhang, zhangwj@nuist.edu.cn
}

associated with the WPSH interannual variations. A warmer (colder) warm pool and thus enhanced (weakened) local convections could excite a low-level anomalous cyclone (anticyclone), which tends to shift the WPSH more northward and westward (southward and eastward) (e.g., Nitta 1987; Lu 2001). It is well known that the warm pool sea surface temperature (SST) and associated convection conditions are largely dependent on the El Niño-Southern Oscillation (ENSO) state (e.g., Picaut et al. 1996), the dominant interannual climate variability resulting from coupled ocean-atmosphere interactions in the tropical Pacific. Therefore, the ENSO and WPSH exhibit a close relationship and their physical linkages have been extensively investigated (e.g., Zhang et al. 1996; Wang and Zhang 2002; Wang et al. 2013; Xiang et al. 2013). During the El Niño developing autumn, the negative SST anomalies in the tropical western Pacific can trigger a western North Pacific anticyclone (WNPAC) and favors a strengthened WPSH (Zhang et al. 1996; Wang 
et al. 2000; Wang and Zhang 2002). This atmospheric teleconnection develops rapidly in late autumn and persists until the following spring and early summer during El Niño episodes through local WNP windevaporation-SST feedback (e.g., Wang et al. 2000) or socalled combination-mode mechanism (e.g., Stuecker et al. 2015; Zhang et al. 2016). Meanwhile, the previous winter El Niño-induced tropical Indian Ocean (IO) warming can persists through summer and anchors the WNPAC by exciting an atmospheric Kelvin wave in the WNP (IO capacitor effect; Xie et al. 2009).

The WPSH also exhibits prominent interdecadal variability; for example, it has been argued that it experienced a decadal change in the late 1970s (e.g., Hu 1997; Gong and Ho 2002; He and Gong 2002). Compared with the prior period, the WPSH tends to be stronger and shifted southwestward during the later period. Accordingly, southern China has experienced a warmer and wetter condition after the late 1970s (He and Gong 2002). The decadal WPSH variation around the late 1970s is argued to be associated with enhanced heating in the Indo-Pacific warm pool (e.g., Zhou et al. 2009). Another argument is that the northward movement and enhancement of the baiu associated heating intensifies the upper-tropospheric ridge and shifts the WPSH northward due to the baroclinic intensification along the baiu rainband (Matsumura et al. 2015). However, several studies proposed that this decadal westward extension of the WPSH is just a manifestation of global warming (Wu and Wang 2015; Huang and $\mathrm{Li}$ 2015; He et al. 2015). When the WPSH is measured by its dynamic definition such as vorticity, the boreal summer WPSH displays no remarkable decadal change in its intensity and location since the late 1970s.

Recently, two leading modes have been extracted for the large spatial-scale pattern associated with the WPSH (Wang et al. 2013). The first mode is characterized by a consistent sign of the geopotential height covering the entire Asian-Australian monsoon region. The second mode exhibits a dipole pressure pattern with opposite sign in the WNP and IO. In particular, the relative importance of these two leading modes is changed around the late 1990s with the previous second mode becoming the dominant one in the recent period (Huang et al. 2018). In accordance, the climate response to the WPSH has also been changed over the East Asian and Indian summer monsoon regions. At present, the mechanisms for the decadal shift of the WPSH dominant modes around the late 1990s have not been clearly illustrated. It is notable that ENSO also has experienced a prominent decadal change around the late 1990s. A new type of El Niño has been observed to occur more frequently with the air-sea action center located in the central Pacific
(CP), which differs considerably from the traditional El Niño that features a SST anomaly center over the eastern Pacific (EP) (Larkin and Harrison 2005; Ashok et al. 2007; Kao and Yu 2009; Kug et al. 2009; Yeh et al. 2009; Zhang et al. 2014). Some studies argued that the CP warming has become the dominant mode in the tropical Pacific since the late 1990s with relatively weaker amplitude and shorter oscillating period (McPhaden et al. 2011; Xiang et al. 2013; Wang and Ren 2017).

It is compelling to hypothesize that the WPSH decadal shift around the late 1990s may be related to changes of the tropical Pacific SST variability, since the tropical Pacific SST is a key factor affecting the WPSH. Whether these two phenomena are closely associated deserves scientific attention for improving the seasonal prediction of the WPSH. The purpose of this present study is to investigate the possible reasons of the decadal shift of the WPSH around the late 1990s. Our analyses show that this decadal shift can be largely attributed to the ENSO regime change. In the remainder of this paper, section 2 introduces the data, methodology, and definition of ENSO events. The WPSH decadal shift around the late 1990s is described in section 3, and the related decadal changes of the ENSO-associated SST in the tropical Pacific are also shown. In section 4, we present an important role of the ENSO regime change on the decadal shift of the WPSH. The major conclusions are summarized and discussed in section 5 .

\section{Data and methodology}

The monthly atmospheric circulation datasets (19792016) used in this study are derived from the National Centers for the Environmental Prediction-National Center for the Atmospheric Research (NCEP-NCAR) reanalysis (Kalnay et al. 1996). The precipitation data are taken from Climate Prediction Center Merged Analysis of Precipitation (CMAP) (Xie and Arkin 1997). The SST anomalies (1979-2016) are examined based on the global sea ice and sea surface temperature analyses from the Hadley Centre (HadISST1) provided by the Met Office (Rayner et al. 2003). The horizontal resolutions of the SST and atmospheric circulation datasets are $2.5^{\circ} \times 2.5^{\circ}$ and $1^{\circ} \times 1^{\circ}$, respectively. Anomalies for all variables are defined as the deviation from the long-term climatological mean (1979-2016) and long-term trends are removed. To focus on the interannual variability of the WPSH, a 7-yr high-pass Fourier filter was applied to each dataset. Note that our qualitative conclusion remains the same even with nonfiltering data. All statistical significance tests were performed based on the Student's $t$ test.

The WPSH index (WPSHI) measuring the WPSH intensity is defined as the boreal summer (JJA) mean 
of 850-hPa geopotential height (H850) anomaly averaged over the interannual variability center of the WPSH $\left(15^{\circ}-25^{\circ} \mathrm{N}, 115^{\circ}-150^{\circ} \mathrm{E}\right)$, following the previous study (Wang et al. 2013). ENSO events are defined by a threshold of \pm 0.5 standard deviations of the Niño-3.4 index (SST anomaly averaged over the region $5^{\circ} \mathrm{S}-5^{\circ} \mathrm{N}$, $120^{\circ}-170^{\circ} \mathrm{W}$ ) during the winter (DJF) season. According to this definition, nine El Niño events (1982/83, 1986/87, 1991/92, 1994/95, 1997/98, 2002/03, 2004/05, 2009/10, 2015/16) and ten La Niña events (1983/84, 1984/85, 1988/89, 1995/96, 1998/99, 2000/01, 2005/06, 2007/08, 2010/11, 2011/12) over the period of 1979-2016 are selected. The ENSO years listed here correspond to year (0)/year (1), where 0 and 1 indicate the developing and decaying year of ENSO, respectively. Further, four EP El Niño events $(1982 / 83,1986 / 87,1991 / 92,1997 / 98)$ and five CP El Niño events (1994/95, 2002/03, 2004/05, 2009/10, 2015/16) are identified based on the equatorial Pacific precipitation anomaly evolutions. ENSO associated SST anomalies can force the atmosphere through the local convection. Thus, the location of equatorial Pacific convection can be used as an effective indicator when attempting to classify two types of El Niño in terms of the atmospheric teleconnection (e.g., Zhang et al. 2013; Johnson and Kosaka 2016). For the nine El Niño events, precipitation anomalies are all located over the western equatorial Pacific during the developing years. After their mature phases, four of them extend eastward in late winter (Figs. 1a-d), while other five events do not show this extension and evolve in situ (Figs. 1e-i). It can also be seen in Fig. 2 that in late winters, those four El Niño events (1982/83, 1986/87, 1991/92, 1997/98) show strong precipitation anomalies over the eastern equatorial Pacific. In contrast, the precipitation anomaly centers of other five El Niño events (1994/95, 2002/03, 2004/05, 2009/10, 2015/16) are maintained over the central-towestern equatorial Pacific with relatively small precipitation anomalies over the eastern equatorial Pacific.

\section{Decadal shift of the leading mode for the WPSH and tropical Pacific SST}

Figure 3 shows the two leading modes of summer (JJA) H850 in the Asian-Australian monsoon region $\left(20^{\circ} \mathrm{S}-40^{\circ} \mathrm{N}, 30^{\circ} \mathrm{E}-180^{\circ}\right)$ through the empirical orthogonal function (EOF) analysis. EOF1 accounts for $33.0 \%$ variance and is characterized by a consistent uniform pattern over the entire region with the center stretching from the WNP to South Asia (Fig. 3a). EOF2 with 24.3\% explained variance features a dipole structure with opposite pressure anomalies over the WNP and IO (Fig. 3b). The 13-yr-window running correlations of the WPSHI with principal components $\mathrm{PC} 1$ and $\mathrm{PC} 2$ are calculated and displayed in Fig. 3d. We employ a bootstrapped significance test (Hesterberg et al. 2003) for the 13-yr running correlation by considering possible impacts of randomness, and results are similar to the Student's $t$ test (Fig. 3d). One can see that the correlations exhibit prominent decadal variations. While PC1 shows gradually decreased association with the WPSHI, the relationship between PC2 and the WPSHI gradually strengthens. After 1998, the correlation coefficients of the WPSHI with PC2 become higher than that with PC1, indicating that the WPSH is mainly dominated by the second mode in the recent period. Since the impact of the second mode on the WPSH became dominant after the 1998, we here choose the year 1998 as the change year and divide the whole period into two periods (1979-98 and 1999-2016), which is roughly consistent with the previous studies (Huang et al. 2018).

As the periodicity is one important feature of the variability, we here conduct a power spectrum analysis on the WPSH in Fig. 4. It is found that the summer WPSH index exhibits significant 2-3-yr and 3-5-yr oscillating periods (Fig. 4a), consistent with the previous studies (Sui et al. 2007; Wu and Zhou 2008; Chung et al. 2011; Wang et al. 2017). Since the change of the leading mode of the WPSH is our focus in this study, we then investigate the main oscillating periods of the PC1 and PC2 in these two separated periods (i.e., 1979-98 and 1999-2016). It is shown that PC1 during 1979-98 and PC2 during 1999-2016 display 5-yr and 2-3-yr oscillating periods, respectively (Figs. $4 \mathrm{~b}, \mathrm{c}$ ). We also checked the main oscillating periods of PC2 in the years 1979-98 and PC1 in the years 1999-2016 respectively. They both oscillate at $\sim 5$ years (not shown), suggesting that the main period of PC2 rather than PC1 has changed in the late 1990s. Since the WPSH is dominated by the PC2 in the 1999-2016 period, the WPSH oscillates relatively faster than that during the 1979-98 period.

As illustrated in the introduction, the tropical Pacific SST is a key factor affecting the intensity, structure, and horizontal position of the WPSH. Previous studies argued that the CP ENSO has become the dominant mode in the tropical Pacific since the late 1990s with relatively weaker amplitude and shorter oscillating period (McPhaden et al. 2011; Xiang et al. 2013; Wang and Ren 2017). To figure out the possible role of the tropical Pacific SST anomalies on the WPSH, we perform a singular value decomposition (SVD) analysis on the summer (JJA) 850-hPa geopotential height over the Asian-Australian monsoon domain $\left(20^{\circ} \mathrm{S}-40^{\circ} \mathrm{N}, 30^{\circ} \mathrm{E}-\right.$ $\left.180^{\circ}\right)$ and preceding winter (DJF) tropical Pacific $\left(30^{\circ} \mathrm{S}-\right.$ $\left.30^{\circ} \mathrm{N}, 120^{\circ} \mathrm{E}-70^{\circ} \mathrm{W}\right) \mathrm{SST}$ anomalies during the two periods of 1979-98 and 1999-2016, respectively. During the former period, the leading SVD mode (68.6\% variance) of the $850-\mathrm{hPa}$ geopotential height anomalies is characterized 


\section{Precipitation evolution}

(a)

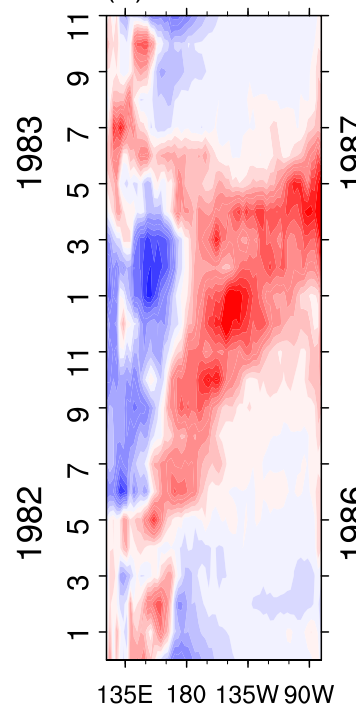

(b)

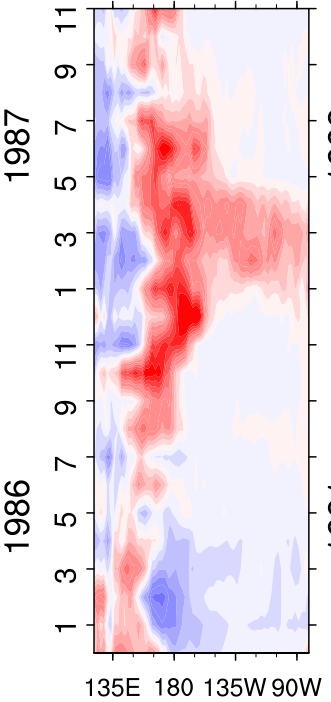

(e)

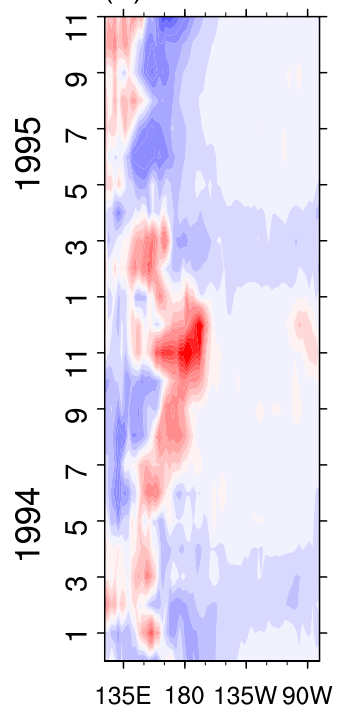

(f)

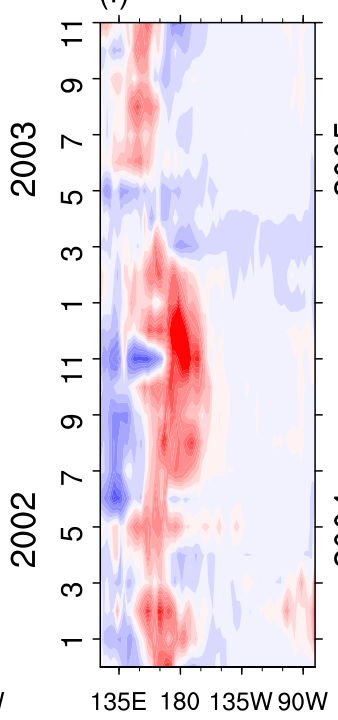

(g)

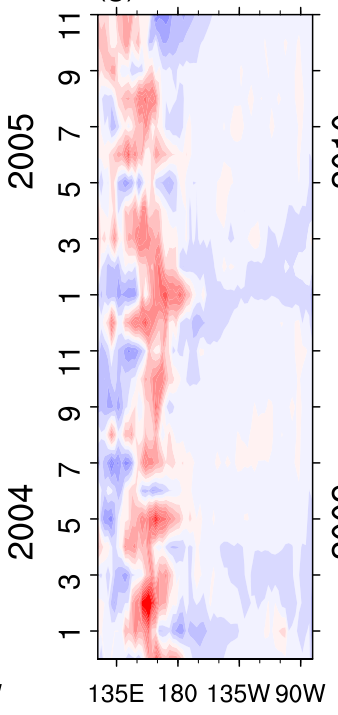

(c)

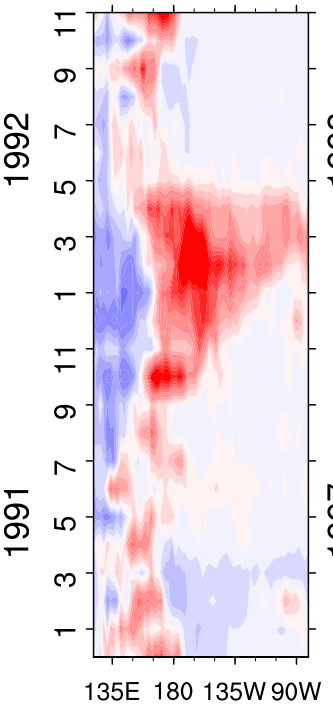

(h) (d)

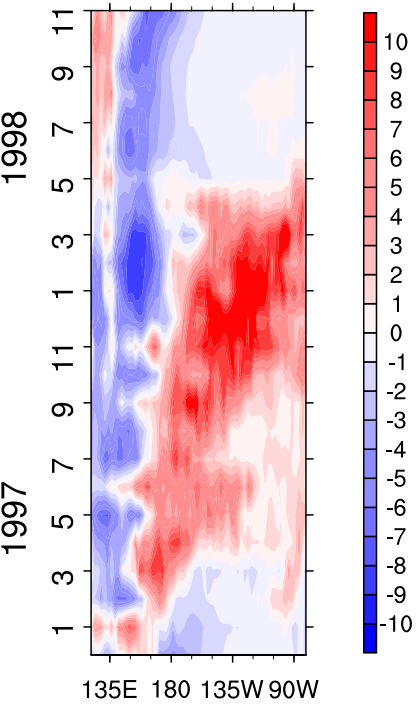

FIG. 1. Longitude-time diagrams of the equatorial $\left(2^{\circ} \mathrm{S}-2^{\circ} \mathrm{N}\right)$ precipitation anomaly for nine $\mathrm{El}$ Niño events.

by a uniform pattern over the entire region (Fig. 5a) and the tropical Pacific SST anomalies exhibit an EP ENSOlike pattern, with maximum SST center located in the eastern equatorial Pacific (Fig. 5c). During 1999-2016, the dominant SVD mode of the WPSH-related circulation pattern is changed from a uniform to a dipole pattern (Fig. 6a), accounting for $55.5 \%$ of the total variance, accompanied by the CP ENSO-like SST anomaly mode with maximum SST anomalies located mainly in the central equatorial Pacific (Fig. 6c). Their cross regressions display almost same patterns (Figs. 5b,d, 6b,d). Also, EOF analyses are applied to the winter tropical
Pacific SST anomalies during the two periods of 1979-98 and 1999-2016, and the dominant SST modes are similar with those based on the SVD analyses (not shown). Meanwhile, power spectrum analyses show that the leading mode of the winter tropical Pacific SST anomalies for the former and latter period oscillates at 4-5 years and 2-3 years, respectively (not shown), which are consistent with that of the WPSH. Both temporal and spatial characteristics of the 850-hPa geopotential height and the tropical Pacific SST imply that the WPSH decadal variation is highly correlated with the ENSO decadal change. It is easy to expect that this concurrent ENSO decadal 


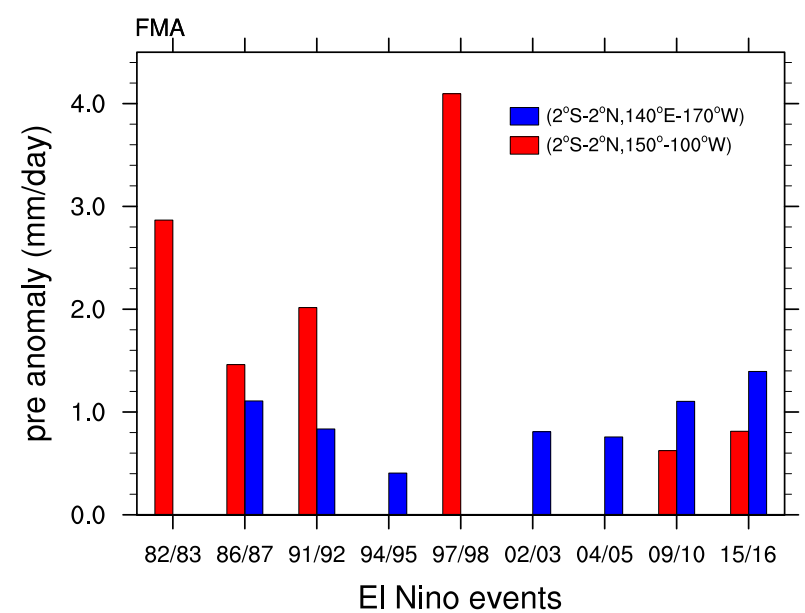

FIG. 2. Normalized area-averaged precipitation anomalies $\left(\mathrm{mm} \mathrm{day}^{-1}\right)$ over the eastern equatorial Pacific $\left(2^{\circ} \mathrm{S}-2^{\circ} \mathrm{N}, 150^{\circ}-100^{\circ} \mathrm{W}\right.$; red) and the western equatorial Pacific $\left(2^{\circ} \mathrm{S}-2^{\circ} \mathrm{N}, 140^{\circ} \mathrm{E}-170^{\circ} \mathrm{W}\right.$; blue) during El Niño late winter seasons (February-April).

change could have contribution in shaping the decadal variation of the WPSH temporal-spatial features.

We further perform cross-power spectrum analysis between the PC1 of WPSH and the preceding winter Niño-3.4 index during 1979-98, and PC2 of WPSH and the preceding winter Niño-3.4 index during 1999-2016.
It is found that the dominant coherence periodicity between them appears at 4-6 years and 2-3 years, respectively (Fig. 7). It again supports that the preceding ENSO and WPSH is significantly correlated and the ENSO regime shift could play an important role for the WPSH decadal change.

To examine the ENSO linkage with WPSH during its developing summers, we conduct a similar SVD analysis between the summer (JJA) geopotential height and subsequent winter (DJF) tropical Pacific SST anomalies during two periods of 1979-98 and 1999-2016. The geopotential height anomalies are characterized by different amplitudes (see next section) but similar dipole patterns during these two periods. Meanwhile, the corresponding SST anomalies also show prominent decadal variations with its maximum SST center shifting from the eastern to central equatorial Pacific (not shown). Since ENSO events are both accompanied with a WPSH dipole structure in the developing summer, the cross power spectrum analysis is performed between the WPSH PC2 and subsequent winter (DJF) Niño-3.4 index during the two periods. Results show that the dominant coherence periodicity between them appears at 4-6 years and 2-4 years, respectively (not shown), which are almost the same as that in Fig. 7. Overall, the SVD and cross power spectrum analyses results indicate that the WPSH

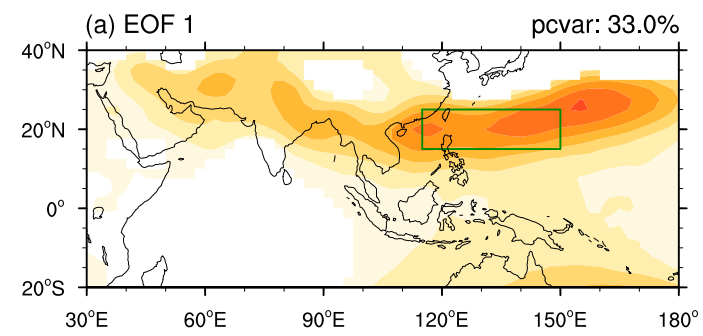

(c) WPSHI\&PC1\&PC2

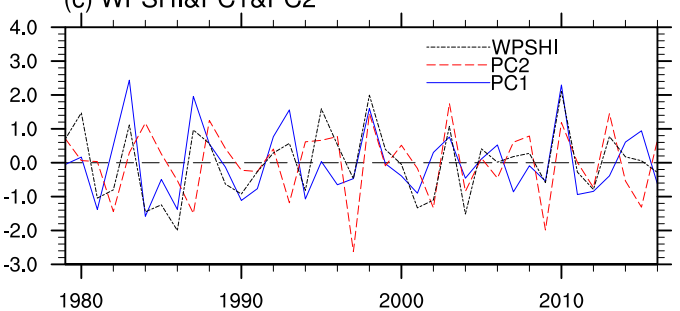

(d) 13-year running correlation

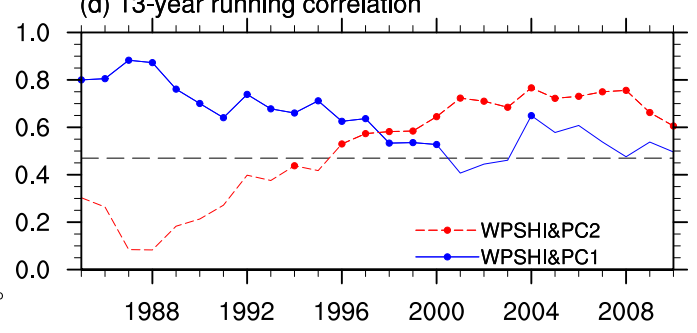

FIG. 3. Regressed spatial pattern of the (a) EOF1 and (b) EOF2 mode derived from boreal summer (JJA) 850$\mathrm{hPa}$ geopotential height anomalies (shading; in m) over the Asian-Australian monsoon domain $\left(20^{\circ} \mathrm{S}-40^{\circ} \mathrm{N}, 30^{\circ} \mathrm{E}-\right.$ $180^{\circ}$ ) during 1979-2016 (only showing values that are significant at the $90 \%$ confidence level). (c) The standardized time series of PC1 (blue line), PC2 (red line), and the WPSH index (WPSHI; black line). The green boxes in (a) and (b) denote the region where the WPSHI is defined. (d) The time evolution of the 13-yr running correlation of WPSHI with PC1 (blue line) and PC2 (red line). The black dashed line denotes the $90 \%$ confidence level based on the two-tailed Student's $t$ test and the solid circles denote that the running correlation coefficients are significant at the $90 \%$ confidence level with a bootstrapped test. 
(a) WNPSH Index

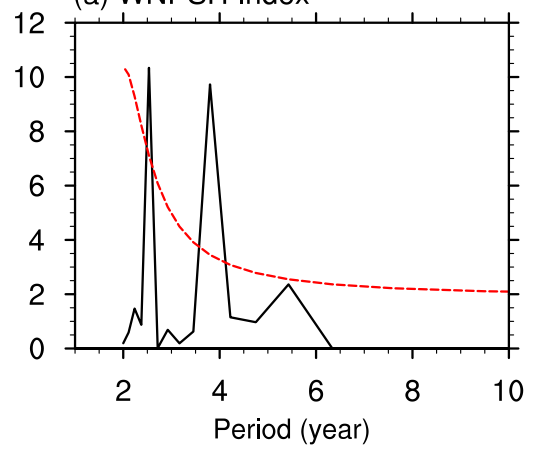

(b) PC1 pre

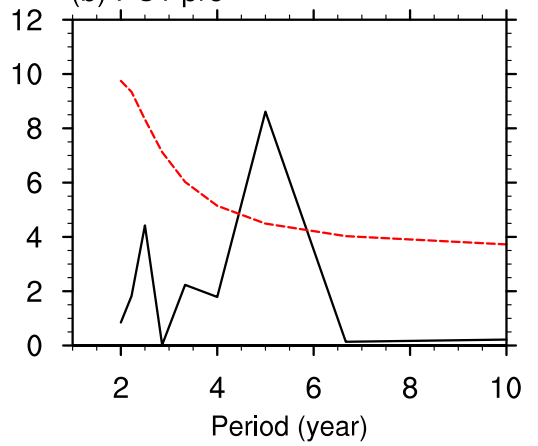

(c) PC2 post

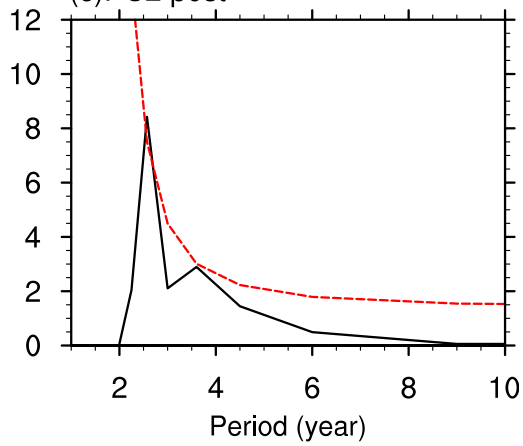

FIG. 4. Power spectrum of the summer WPSH index during (a) 1979-2016, (b) 1979-98, and (c) 1999-2016. The red dashed line denotes the $90 \%$ confidence level.

and ENSO are significantly correlated, and the ENSO regime shift could be responsible for the decadal change of the WPSH temporal-spatial features during both its developing and decaying summers.

\section{Possible contribution of ENSO regime shift on the WPSH decadal change}

\section{a. Contribution of more frequent CP El Niño on the WPSH decadal change}

To examine the possible contributions of ENSO to the WPSH decadal change, we first composite the PC1 and
PC2 during all ENSO developing and decaying summers for the two periods (Fig. 8). During the El Niño developing summer in the 1979-98 period, the composite $\mathrm{PC} 1$ and $\mathrm{PC} 2$ values are negative and comparable (red hollow circle in Fig. 8a and "PRE" red border bar in Fig. 8c), whereas during the 1999-2016 period the value of $\mathrm{PC} 1$ is close to zero and $\mathrm{PC} 2$ becomes significantly stronger (red solid circle in Fig. 8a and "POST" red border bar in Fig. 8c). During El Niño decaying summer in the former period, the composite PC1 is relatively stronger and $\mathrm{PC} 2$ is very weak (blue hollow circle in Fig. 8a and "PRE" blue border bar in Fig. 8d);

\section{$1979-1998$}

(a) HGTA regressed on HGT SVD PC1

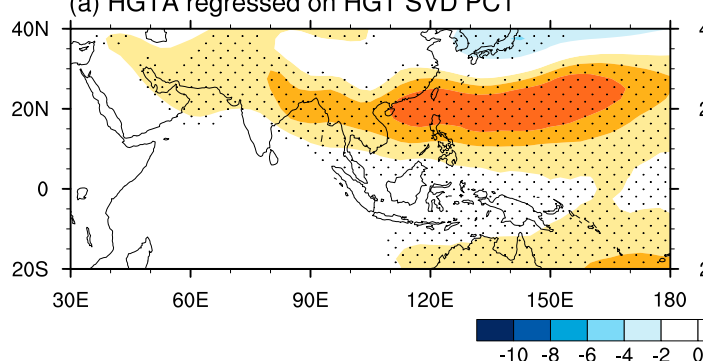

(b) HGTA regressed on SST SVD PC1

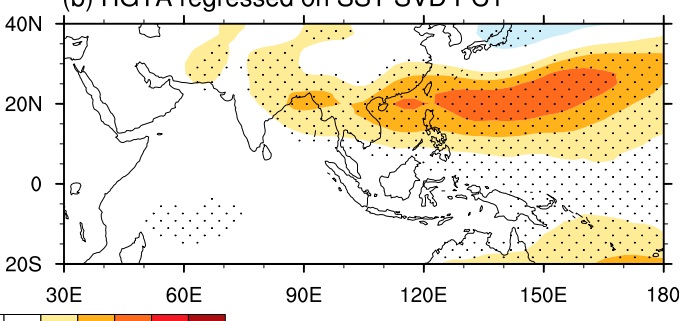

(c) SSTA regressed on SST SVD PC1

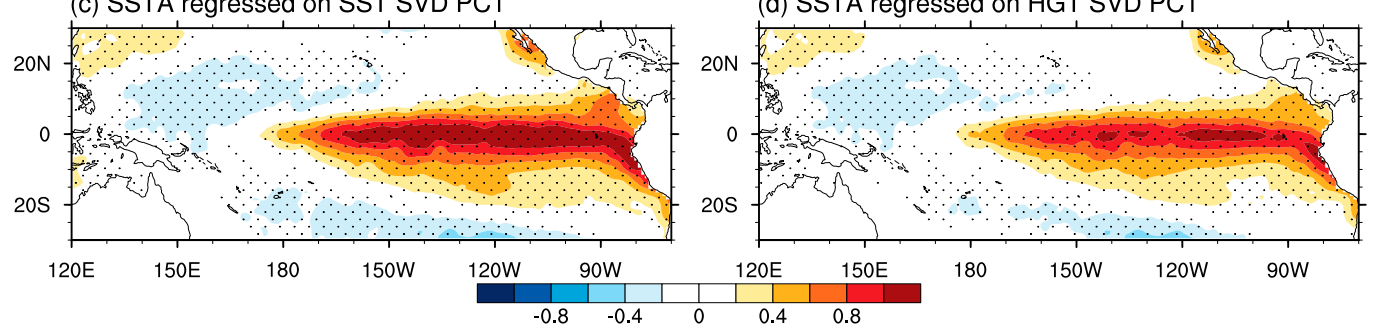

FIG. 5. (a),(b) Boreal summer (JJA) 850-hPa geopotential height anomalies and (c),(d) preceding winter (DJF) SST anomalies regressed onto the standardized SVD-PC1 during 1979-98. The SVD is performed between the 850hPa geopotential height anomalies over the Asian-Australian monsoon domain $\left(20^{\circ} \mathrm{S}-40^{\circ} \mathrm{N}, 30^{\circ} \mathrm{E}-180^{\circ}\right)$ and SST anomalies over the tropical Pacific domain $\left(30^{\circ} \mathrm{S}-30^{\circ} \mathrm{N}, 120^{\circ} \mathrm{E}-70^{\circ} \mathrm{W}\right)$ during $1979-98$. The stippled area denotes the corresponding values are significant at the $90 \%$ significance level. 
$1999-2016$

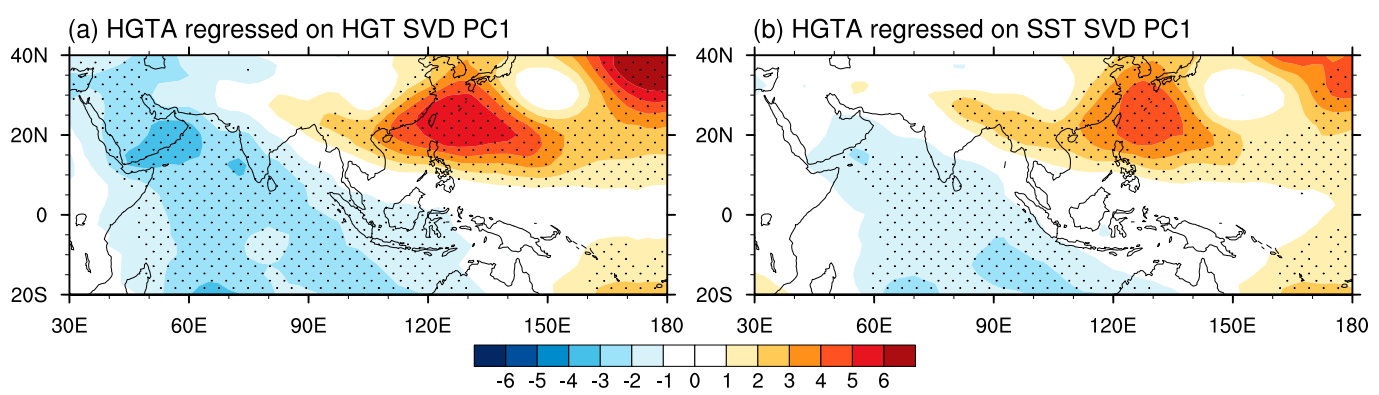

(c) SSTA regressed on SST SVD PC1

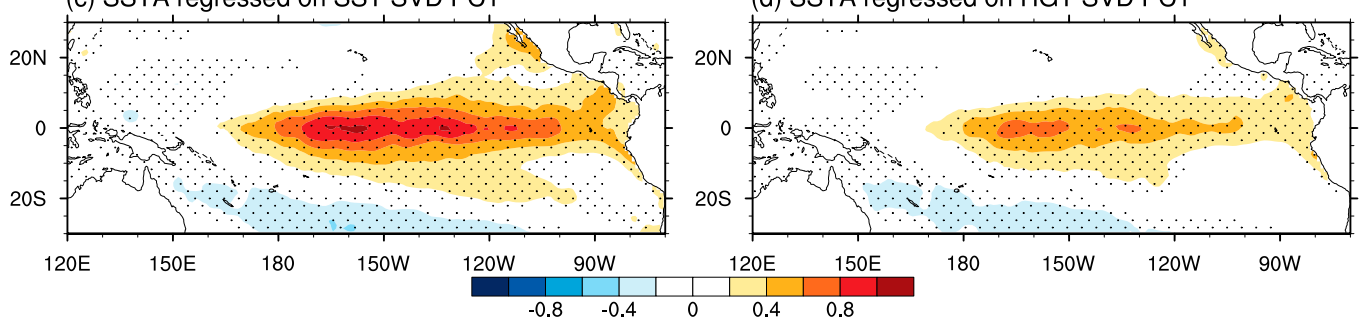

FIG. 6. As in Fig. 5, but for the 1999-2016 period.

however, in the later period the PC1 becomes much weaker and the PC2 enhances obviously (blue solid circle in Fig. 8a and "POST" blue border bar in Fig. 8d). These results suggest that El Niño-associated EOF2 intensity is strongly enhanced and associated EOF1 intensity is largely weakened in the later period compared with the former period, for both the developing and decaying summers. It means the dipole pattern (represented as the EOF2) has become the dominant mode of the WPSH during El Niño summers in the later period. Meanwhile, the composite PC1 and PC2 during the La Niña developing and decaying summers are both weakened and exhibit no enhancement of EOF2 associated circulation in the later period (Fig. 8b). It seems that the decadal shift of the WPSH main mode is mainly associated with the El Niño events rather than the La Niña events. So, we next focus on the El Niño state and inspect different impacts of the El Niño on the WPSH for the former and later periods.
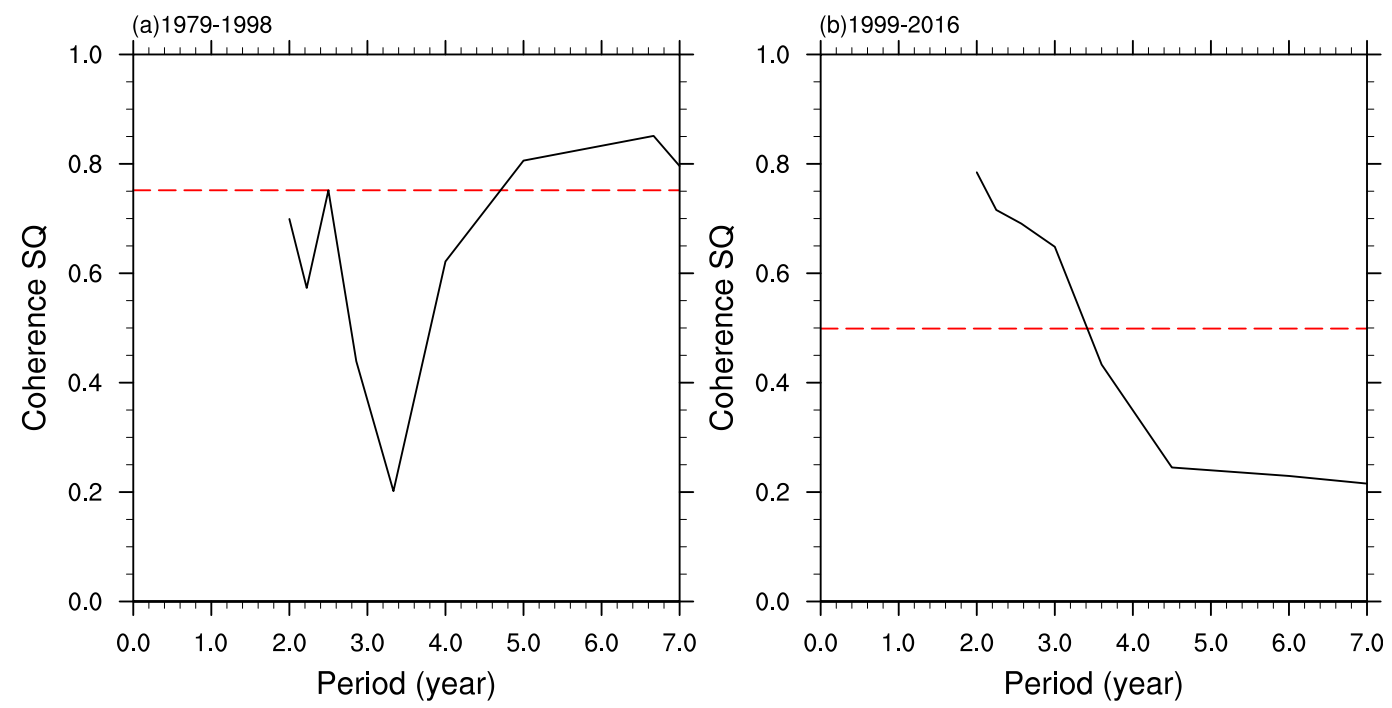

FIG. 7. Coherence spectrum between (a) PC1 and preceding winter (DJF) Niño-3.4 index during 1979-98 and (b) PC2 of WPSH and the preceding winter (DJF) Niño-3.4 index during 1999-2016. The red dashed line denotes the $90 \%$ confidence level. 
(a) El Nino events

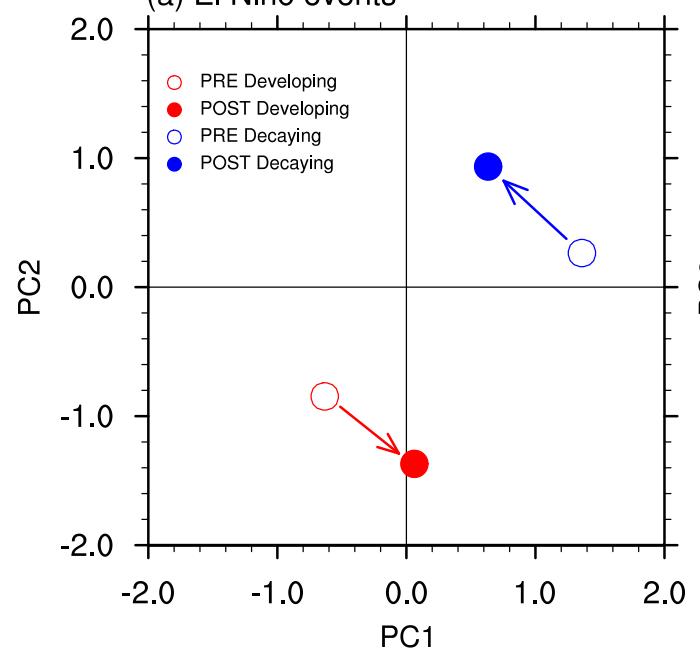

(c) El Nino events Developing

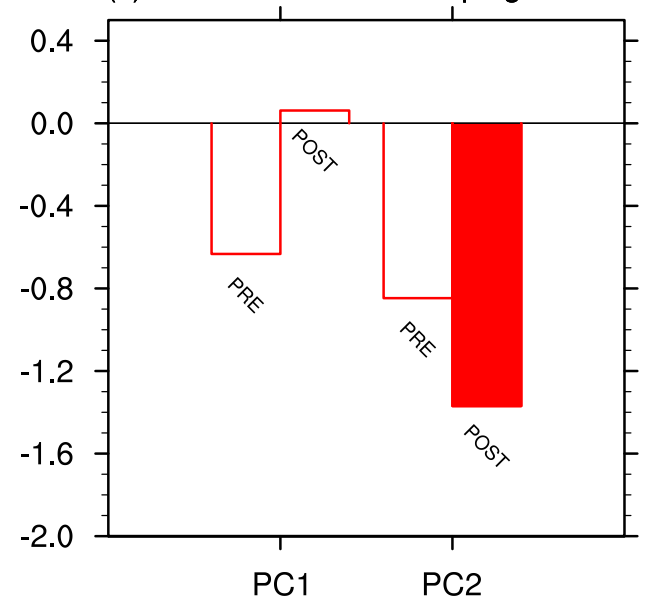

(b) La Nina events

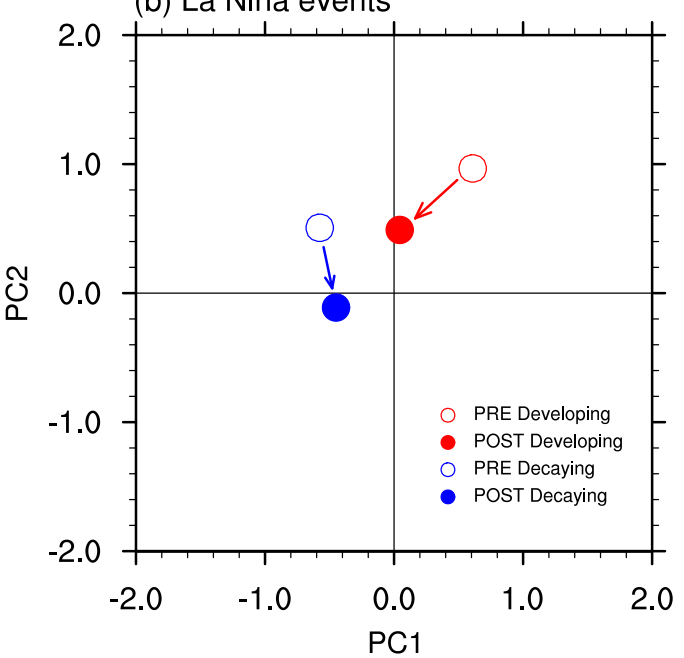

(d) El Nino events Decaying

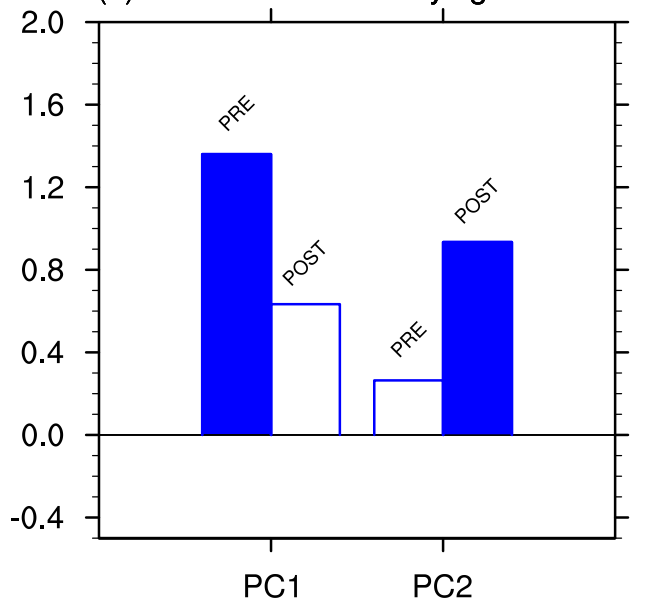

FIG. 8. Scatterplot of the composite WPSH PC1 and PC2 during 1979-98 (PRE; hollow circle) and 1999-2016 (POST; solid circle) of (a) El Niño and (b) La Niña events. The blue and red colors denote the ENSO developing and decaying summers, respectively. Also shown are composite WPSH PC1 and PC2 during 1979-98 and 1999-2016 corresponding to the (c) developing (red border bar) and (d) decaying (blue border bar) summer of El Niño events, respectively. The solid bars denote that the composite is significant at the $90 \%$ significance level.

We further display the composite $\mathrm{PC} 1$ and $\mathrm{PC} 2$ in the developing and decaying summers for the two types of El Niño events (Fig. 9). A significant positive PC1 value appears during the EP El Niño decaying summer and a negative $\mathrm{PC} 2$ value can be detected during the EP El Niño developing summer. The PC2 values are relatively smaller than the PC1 values. In contrast, no significant PC1 anomaly is shown associated with CP El Niño. However, significant PC2 anomalies are displayed during both $\mathrm{CP}$ El Niño developing and decaying summers with reversed sign. These results further confirm our previous results that the EP El Niño is accompanied mainly by the WPSH EOF1 associated variability while the CP El Niño is closely related to the WPSH EOF2 associated variability. Since the late 1990s, the CP El Niño has occurred much more frequently and EP El Niño has become less common ( 4 of 5 El Niño events are the EP El Niño in 1979-98 and all four El Niño events are the CP El Niño; see Table 1). Therefore, the WPSH main variability has changed from the EOF1 pattern to the EOF2 pattern due to the ENSO regime change.

We further extend our study period (1951-2016) to examine whether the main conclusion remains the same for more samples. We project the 1951-2016 850-hPa geopotential height anomalies onto the spatial patterns of the leading WPSH EOFs to obtain PC time series and again composite $\mathrm{PC} 1$ and $\mathrm{PC} 2$ in the developing and decaying summers for the two types of El Niño events. 


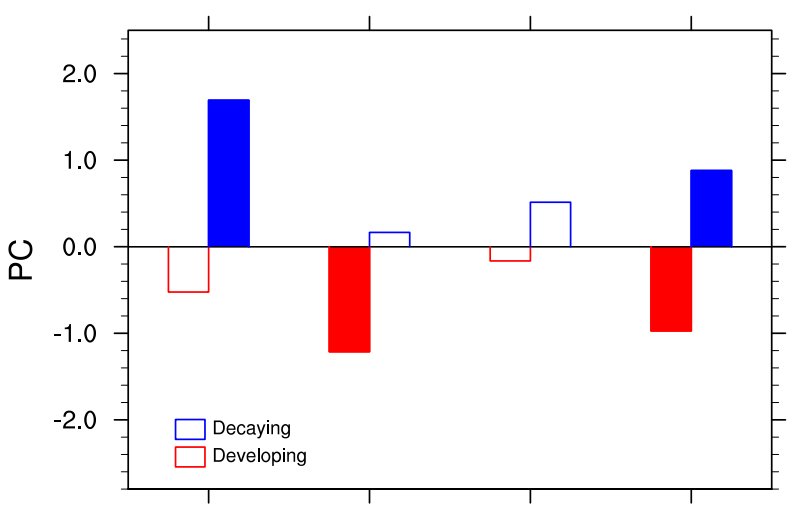

FIG. 9. Composite WPSH PC1 and PC2 during 1979-2016 corresponding to the developing (red border bar) and decaying (blue border bar) summer of two types of the El Niño events. The solid bars denote that the composite is significant at the $90 \%$ significance level.

In this relatively longer period, eight EP El Niño events (1957/58, 1968/69, 1972/73, 1976/77, 1982/83, 1986/87, 1991/92, 1997/98) and nine CP El Niño events (1963/64, 1965/66, 1969/70, 1977/78, 1994/95, 2002/03, 2004/05, 2009/10, 2015/16) are identified based on the equatorial Pacific precipitation anomaly evolutions (also see our definition in section 2). The same results can be derived (not shown), further confirming our main conclusion.

\section{b. Discussion on possible reasons for different impacts of two types of El Niño on the WPSH}

To further discuss possible reasons for different WPSH responses to the two types of El Niño events, we show in Fig. 10 the composite SST and atmospheric circulation anomalies during the developing and decaying summers of the two types of El Niño events.

During the EP El Niño developing summer, significantly positive SST anomalies develop in the central and eastern equatorial Pacific, whereas the western tropical Pacific is marked by sporadic weak cold SST anomalies and IO SST anomalies are almost absent (Fig. 10a). The equatorial Pacific warming usually triggers anomalous cyclonic circulation over the WNP and central Pacific region (e.g., Wang and Zhang 2002) as a Rossby wave response (Matsuno 1966; Gill 1980). Meanwhile, the central and eastern equatorial Pacific warming leads to subsidence over the Maritime Continent and IO via a weakened Walker circulation (Kumar et al. 1999, 2006), giving rise to the anticyclonic wind anomalies in the low level of the IO. So, the $850-\mathrm{hPa}$ geopotential heights over the WNP and IO are opposite in sign and thus a west-east dipole structure similar to the WPSH EOF2 pattern tends to appear (Fig. 10a). During the EP El Niño decaying summer, significantly positive SST anomalies
TABLE 1. El Niño events for the PRE and POST periods during the years 1979-2016.

\begin{tabular}{lcc}
\hline \hline & $1979-98$ & $1999-2016$ \\
\hline EP El Niño events & $1982 / 83,1986 / 87$, & \\
& $1991 / 92,1997 / 98$ & \\
CP El Niño events & $1994 / 95$ & $2002 / 03,2004 / 05$, \\
& & $2009 / 10,2015 / 16$ \\
\hline
\end{tabular}

disappear in the central Pacific and only small-scale warming is maintained in the eastern tropical Pacific. In contrast, significant warm SST anomalies in the tropical IO can also excite a strong WNPAC on a large scale via the IO delayed capacitor effect (Xie et al. 2009), resembling the WPSH EOF1 pattern (Fig. 10b). The WNP cold SST anomalies could also play some role with regard to the WNPAC through the local air-sea interaction (Wang et al. 2000).

During the CP developing summer, warm SST anomalies appear in the central tropical Pacific and almost no strong SST anomalies can be detected in the western Pacific and IO (Fig. 10c). This central Pacific warming can result into a cyclonic anomaly in the WNP as a Rossby response and simultaneously produce subsidence anomalies over the IO via the Walker circulation. Therefore, negative and positively H850 occurs over the WNP and IO, respectively (Fig. 10c), resembling the WPSH EOF2 pattern (Fig. 10a). During the CP El Niño decaying summer, the eastern equatorial Pacific is already covered by weak negative SST anomalies (Fig. 10d). Very different from the EP El Niño decaying summer, the anomalous WNP cooling and the IO warming cannot be obviously found (Figs. 10d, 11). Therefore, the WNP anticyclone anomalies could be mainly associated with the cold SST anomalies in the eastern equatorial Pacific as a Rossby wave response. Simultaneously, the eastern Pacific cold SST anomalies favor anomalous rising in the IO and thus weakly negative H850 there via a strengthened Walker circulation. In addition, there exist significantly positive SST anomalies in the Maritime Continent (Fig. 10d), which tend to force the anomalous descending motion through local anomalous Hadley circulation and further strengthen the WPSH. Therefore, the WPSH-associated large-scale feature resembles the WPSH EOF2 pattern (a dipole structure).

In general, during the EP El Niño decaying summer, the WPSH tends to exhibit a uniform pattern resembling the EOF1 pattern, whereas it tends to display a dipole pattern similar to the EOF2 pattern during EP El Niño developing summer. In contrast, both CP El Niño developing and decaying summers tend to be accompanied by a dipole pattern of the WPSH similar to the EOF2 pattern. The ENSO associated SST anomalies 
(a) EP El Nino developing JJA ssta

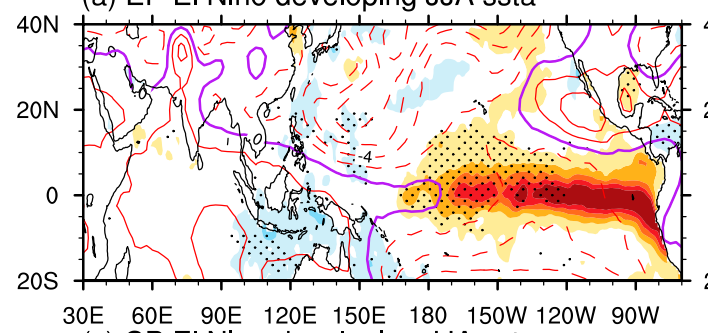

(c) CP El Nino developing JJA ssta (b) EP El Nino decaying JJA ssta

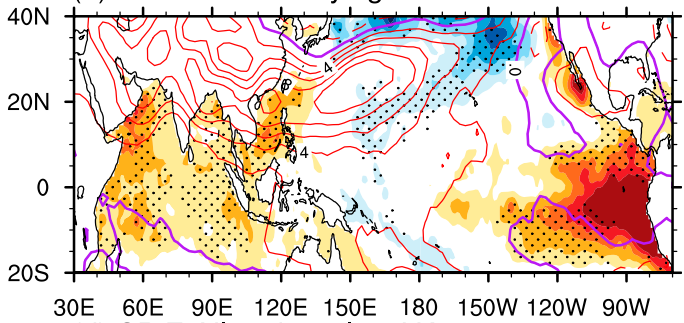

(d) CP EI Nino decaying JJA ssta

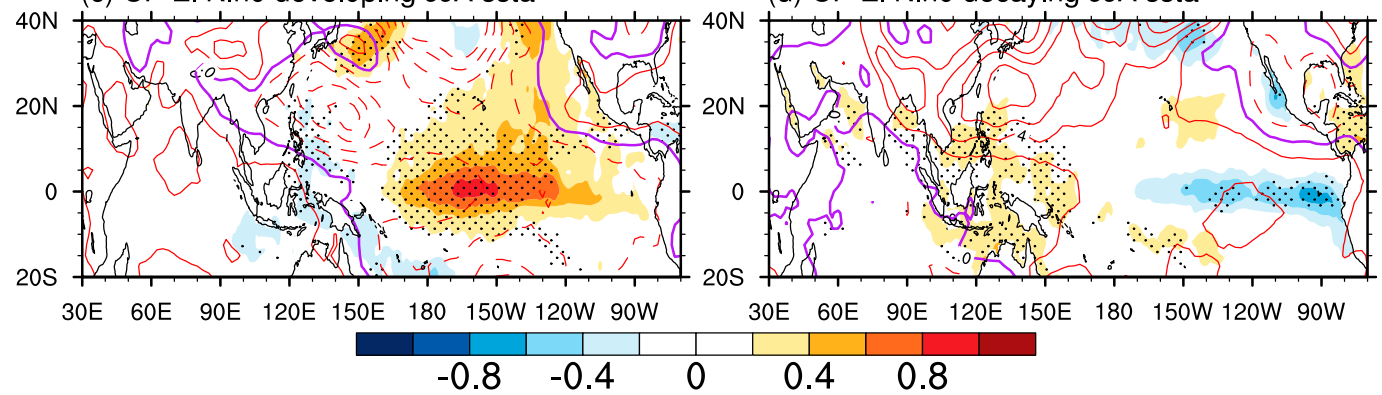

FIG. 10. Composite SST anomalies (shading; in ${ }^{\circ} \mathrm{C}$ ) and 850-hPa geopotential height anomalies (contours; in m; positive values are solid while negative values are dashed) in the (a),(c) developing and (b),(d) decaying summer of the two types of El Niño events: (a),(b) EP El Niño and (c),(d) CP El Niño. The stippled area denotes the corresponding values are significant at the $90 \%$ significance level.

play an important role with regard to the WPSH spatial patterns.

\section{Summary and discussion}

The present study demonstrates that the significant variations of the WPSH temporal and spatial characteristics around the late 1990s are largely due to the changes of the dominant mode of the air-sea system in the tropical Pacific. In the pre-1998 period, the WPSH is dominated by a large-scale uniform pattern with an $\sim 5$-yr oscillating period. In the post-1998 period, the main mode of the WPSH is shifted to the dipole pattern and the oscillating period is shortened to $2-3$ years. The WPSH decadal change corresponds to the ENSO regime shift from the EP ENSO mode with a period of 4-5 years to the CP ENSO mode with a period of 2-3 years. The WPSH tends to display a uniform pattern resembling the EOF1 pattern during the EP El Niño decaying summer. In contrast, the EP El Niño developing summer and the CP El Niño developing and decaying summers tend to accompany a dipole pattern of the WPSH similar with the EOF2 pattern. It seems that La Niña makes only minor contributions to the WPSH decadal change around the late 1990s. Different WPSH responses to the two types of El Niño are mainly associated with distinct SST anomalies over the central-to-eastern Pacific and also local WNP and IO SST anomalies. Since the CP El Niño has occurred more frequently and EP El Niño becomes less common after the late 1990s, the WPSH main variability has been changed from the EOF1related uniform pattern to the EOF2-related dipole pattern.

Considering important climate impacts of different WPSH leading modes (Huang et al. 2018), we also examine the multimodel performance of the Atmospheric Model Intercomparison Project (AMIP5) in simulating the temporal and spatial features of the WPSH. Among 22

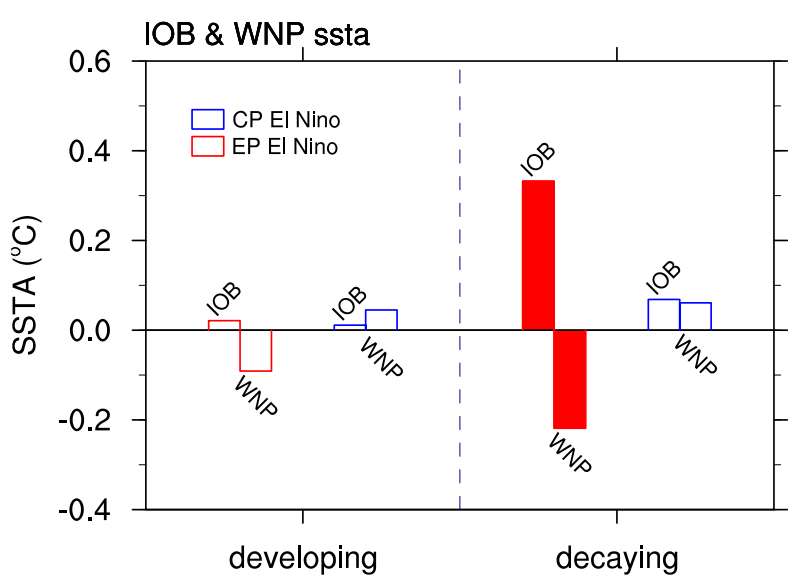

FIG. 11. Composite SST anomalies $\left({ }^{\circ} \mathrm{C}\right)$ in the IO basin $\left(20^{\circ} \mathrm{S}-\right.$ $\left.20^{\circ} \mathrm{N}, 40^{\circ}-100^{\circ} \mathrm{E}\right)$ and $\mathrm{WNP}\left(10^{\circ}-25^{\circ} \mathrm{N}, 150^{\circ} \mathrm{E}-160^{\circ} \mathrm{W}\right)$ in the developing and decaying summer of EP (red border bar) and CP (blue border bar) El Niño events. The solid bars denote the composite is significant at the $90 \%$ significance level. 
AMIP5 models, only three of them can simulate the two modes of the WPSH and there is no decadal shift of relationship between the PCs and WPSHI (not shown). It seems that ability of the AMIP5 models in simulating the Asian atmospheric response to the tropical SST is poor and more efforts are required to improve the simulation capacity. Here we do not consider the coupled simulations from phase 5 of the Coupled Model Intercomparison Project (CMIP5), since they cannot realistically capture the ENSO diversity in the zonal structure (not shown). We also use atmospheric models (i.e., GFDL AM2.1 and NCAR CAM5) to conduct experiments by specifying the ENSO associated SST anomalies in the tropical Pacific. As in the AMIP5 experiments, the models cannot capture the leading EOF modes of the WPSH.

The ENSO regime change around the late 1990s is of great interest in recent research, but its physical reasons remain unclear. For example, one study argued that the background state of the tropical Pacific might be the reason for the ENSO regime change (Xiang et al. 2013). Another argued that the ENSO regime change could be related to the North Atlantic SST anomaly (Ham et al. 2013; Wang et al. 2017). One recent study provides another possible mechanism, namely that the tropic Pacific cold tongue mode may contribute to more frequent occurrence of CP El Niño under global warming ( $\mathrm{Li}$ et al. 2017).

It should be noted that this study mainly explores the possible mechanisms for the decadal variation of the WPSH from a perspective of ENSO regime changes. Influences by other possible forcings, such as tropical Atlantic SST anomaly (e.g., Lu and Dong 2005; Rong et al. 2010; Hong et al. 2014) and Tibetan Plateau snow cover (e.g., Zhang et al. 2004; Wu et al. 2012; Xiao and Duan 2016), may provide some contribution on the WPSH temporal and spatial variations at multiple time scales, which deserves further exploration.

Acknowledgments. This work was supported by the National Key Research and Development Program (2018YFC1506002), the National Nature Science Foundation of China (41675073), and the SOA Program on Global Change and Air-Sea interactions (GASIIPOVAI-03).

\section{REFERENCES}

Ashok, K., S. K. Behera, S. A. Rao, H. Y. Weng, and T. Yamagata, 2007: El Niño Modoki and its possible teleconnection. J. Geophys. Res., 112, C11007, https://doi.org/10.1029/2006JC003798.

Chung, P., C. Sui, and T. Li, 2011: Interannual relationships between the tropical sea surface temperature and summertime subtropical anticyclone over the western North
Pacific. J. Geophys. Res., 116, D13111, https://doi.org/10.1029/ 2010JD015554.

Ding, Y. H., 1994: Monsoons over China. Kluwer, 420 pp.

Gill, A. E., 1980: Some simple solutions for the heat-induced tropical circulation. Quart. J. Roy. Meteor. Soc., 106, 447-462, https:// doi.org/10.1002/qj.49710644905.

Gong, D., and C. Ho, 2002: Shift in the summer rainfall over the Yangtze River valley in the late 1970s. Geophys. Res. Lett., 29, 1436, https://doi.org/10.1029/2001GL014523.

Ham, Y. G., J. S. Kug, J. Y. Park, and F. F. Jin, 2013: Sea surface temperature in the north tropical Atlantic as a trigger for El Niño/Southern Oscillation events. Nat. Geosci., 6, 112-116, https://doi.org/10.1038/ngeo1686.

He, C., T. Zhou, A. Lin, B. Wu, D. Gu, C. Li, and B. Zheng, 2015: Enhanced or weakened western North Pacific subtropical high under global warming? Sci. Rep., 5, 16771, https://doi.org/ 10.1038/srep16771.

He, X., and D. Gong, 2002: Interdecadal change in western Pacific subtropical high and climatic effects. J. Geogr. Sci., 12, 202-209, https://doi.org/10.1007/BF02837475.

Hesterberg, T., S. Monaghan, D. S. Moore, A. Clipson, and R. Epstein, 2003: Bootstrap methods and permutation tests. Companion chapter 18 (standalone) to The Practice of Business Statistics by D. S. Moore, W. H. Freeman and Company, 85 pp.

Hong, C., T. Chang, and H. Hsu, 2014: Enhanced relationship between the tropical Atlantic SST and the summertime western North Pacific subtropical high after the early 1980s. J. Geophys. Res., 119, 3715-3722, https://doi.org/10.1002/2013JD021394.

$\mathrm{Hu}$, Z.-Z., 1997: Interdecadal variability of summer climate over East Asia and its association with 500-hPa height and global sea surface temperature. J. Geophys. Res., 102, 19 403-19412, https://doi.org/10.1029/97JD01052.

Huang, S., 1963: Longitudinal movement of the subtropical anticyclone and its prediction (in Chinese). Acta Meteor. Sin., 33, 320-332.

Huang, Y., and X. Li, 2015: The interdecadal variation of the western Pacific subtropical high as measured by $500 \mathrm{hPa}$ eddy geopotential height. Atmos. Oceanic Sci. Lett., 8, 371-375, https://doi.org/10.3878/AOSL20150038.

, B. Wang, X. Li, and H. Wang, 2018: Changes in the influence of the western Pacific subtropical high on Asian summer monsoon rainfall in the late 1990s. Climate Dyn., 51, 443-455, https://doi.org/10.1007/s00382-017-3933-1.

Johnson, N., and Y. Kosaka, 2016: The impact of eastern equatorial Pacific convection on the diversity of boreal winter El Niño teleconnection patterns. Climate Dyn., 47, 3737-3765, https:// doi.org/10.1007/s00382-016-3039-1.

Kalnay, E., and Coauthors, 1996: The NCEP/NCAR reanalysis project. Bull. Amer. Meteor. Soc., 77, 437-471, https://doi.org/ 10.1175/1520-0477(1996)077<0437:TNYRP > 2.0.CO;2.

Kao, H. Y., and J. Y. Yu, 2009: Contrasting eastern-Pacific and central-Pacific types of ENSO. J. Climate, 22, 615-632, https:// doi.org/10.1175/2008JCLI2309.1.

Kug, J.-S., F.-F. Jin, and S.-I. An, 2009: Two types of El Niño events: Cold tongue El Niño and warm pool El Niño. J. Climate, 22, 1499-1515, https://doi.org/10.1175/2008JCLI2624.1.

Kumar, K. K., B. Rajagopalan, and M. A. Cane, 1999: On the weakening relationship between the Indian monsoon and ENSO. Science, 284, 2156-2159, https://doi.org/10.1126/ science.284.5423.2156.

,-- , M. Hoerling, G. Bates, and M. A. Cane, 2006: Unraveling the mystery of Indian monsoon failure during El Niño. Science, 314, 115-119, https://doi.org/10.1126/science.1131152. 
Larkin, N. K., and D. E. Harrison, 2005: On the definition of El Niño and associated seasonal average U.S. weather anomalies. Geophys. Res. Lett., 32, L13705, https://doi.org/10.1029/ 2005 GL022738.

Lau, K. M., and M. T. Li, 1984: The monsoon over East Asia and its global association-A survey. Bull. Amer. Meteor. Soc., 65, 114-125, https://doi.org/10.1175/1520-0477(1984)065<0114: TMOEAA $>2.0 . \mathrm{CO} ; 2$.

Li, Y., J. Li, W. Zhang, Q. Chen, J. Feng, F. Zheng, W. Wang, and X. Zhou, 2017: Impacts of the tropical Pacific cold tongue mode on ENSO diversity under global warming. J. Geophys. Res. Oceans, 122, 8524-8542, https://doi.org/10.1002/2017jc013052.

$\mathrm{Lu}, \mathrm{R}$., 2001: Interannual variability of the summertime North Pacific subtropical high and its relation to atmospheric convection over the warm pool. J. Meteor. Soc. Japan, 79, 771-783, https://doi.org/10.2151/jmsj.79.771.

— ture anomalies on the summer climate in the western North Pacific during 1997-1998. J. Geophys. Res., 110, D16102, https:// doi.org/10.1029/2004JD005676.

Matsumura, S., S. Sugimoto, and T. Sato, 2015: Recent intensification of the western Pacific subtropical high associated with the East Asian summer monsoon. J. Climate, 28, 2873-2883, https://doi.org/10.1175/JCLI-D-14-00569.1.

Matsuno, T., 1966: Quasi-geostrophic motions in the equatorial area. J. Meteor. Soc. Japan, 44, 25-43, https://doi.org/10.2151/ jmsj1965.44.1_25.

McPhaden, M. J., T. Lee, and D. McClurg, 2011: El Niño and its relationship to changing background conditions in the tropical Pacific Ocean. Geophys. Res. Lett., 38, L15709, https://doi.org/ 10.1029/2011GL048275.

Nitta, T., 1987: Convective activities in the tropical western Pacific and their impact on the Northern Hemisphere summer circulation. J. Meteor. Soc. Japan, 65, 373-390, https://doi.org/ 10.2151/jmsj1965.65.3_373.

Picaut, J., M. Ioualalen, C. Menkes, T. Delcroix, and M. J. McPhaden, 1996: Mechanism of the zonal displacements of the Pacific warm pool: Implications for ENSO. Science, 274, 1486-1489, https:// doi.org/10.1126/science.274.5292.1486.

Rayner, N. A., D. E. Parker, E. B. Horton, C. K. Folland, L. V. Alexander, D. P. Rowell, E. C. Kent, and A. Kaplan, 2003: Global analyses of sea surface temperature, sea ice, and night marine air temperature since the late nineteenth century. J. Geophys. Res., 108, 4407, https://doi.org/10.1029/2002JD002670.

Rong, X., R. Zhang, and T. Li, 2010: Impacts of Atlantic sea surface temperature anomalies on Indo-East Asian summer monsoonENSO relationship. Chin. Sci. Bull., 55, 2458-2468, https:// doi.org/10.1007/s11434-010-3098-3.

Stuecker, M. F., F.-F. Jin, A. Timmermann, and S. McGregor, 2015: Combination mode dynamics of the anomalous northwest Pacific anticyclone. J. Climate, 28, 1093-1111, https://doi.org/ 10.1175/JCLI-D-14-00225.1.

Sui, C., P. Chung, and T. Li, 2007: Interannual and interdecadal variability of the summertime western North Pacific subtropical high. Geophys. Res. Lett., 34, L11701, https://doi.org/10.1029/ 2006 GL029204.

Tao, S., and S. Xu, 1962: Circulation characteristics in association with persistent summer drought and flood in the YangtzeHuaihe River reaches (in Chinese). Acta Meteor. Sin., 32, 1-18. , and L. Chen, 1987: A review of recent research on the East Asian summer monsoon in China. Monsoon Meteorology, C.-P. Chang and T. N. Krishnamurti, Eds., Oxford University Press, 60-92.
Wang, B., and Q. Zhang, 2002: Pacific-East Asian teleconnection. Part II: How the Philippine Sea anomalous anticyclone is established during El Niño development. J. Climate, 15, 3252-3265, https://doi.org/10.1175/1520-0442(2002)015<3252: PEATPI $>2.0 . \mathrm{CO} ; 2$.

_- R. Wu, and X. Fu, 2000: Pacific-East Asian teleconnection: How does ENSO affect East Asian climate? J. Climate, 13, 1517-1536, https://doi.org/10.1175/1520-0442(2000)013<1517: PEATHD $>2.0 . \mathrm{CO} ; 2$.

_ B. Xiang, and J. Y. Lee, 2013: Subtropical high predictability establishes a promising way for monsoon and tropical storm predictions. Proc. Natl. Acad. Sci. USA, 110, 2718-2722, https:// doi.org/10.1073/pnas.1214626110.

Wang, L., J. Yu, and H. Paek, 2017: Enhanced biennial variability in the Pacific due to Atlantic capacitor effect. Nat. Commun., 8, 14887, https://doi.org/10.1038/ncomms14887.

Wang, R., and H. Ren, 2017: The linkage between two ENSO types/modes and the interdecadal changes of ENSO around the year 2000. Atmos. Oceanic Sci. Lett., 10, 168-174, https:// doi.org/10.1080/16742834.2016.1258952.

$\mathrm{Wu}, \mathrm{B}$., and T. Zhou, 2008: Oceanic origin of the interannual and interdecadal variability of the summertime western Pacific subtropical high. Geophys. Res. Lett., 35, L13701, https://doi.org/ 10.1029/2008GL034584.

Wu, L., and C. Wang, 2015: Has the western Pacific subtropical high extended westward since the late 1970s? J. Climate, 28, 5406-5413, https://doi.org/10.1175/JCLI-D-14-00618.1.

Wu, Z., J. Li, Z. Jiang, and T. Ma, 2012: Modulation of the Tibetan Plateau snow cover on the ENSO teleconnections: From the East Asian summer monsoon perspective. J. Climate, 25, 2481-2489, https://doi.org/10.1175/JCLI-D-11-00135.1.

Xiang, B., B. Wang, and T. Li, 2013: A new paradigm for the predominance of standing central Pacific warming after the late 1990s. Climate Dyn., 41, 327-340, https://doi.org/10.1007/ s00382-012-1427-8.

Xiao, Z., and A. Duan, 2016: Impacts of Tibetan Plateau snow cover on the interannual variability of the East Asian summer monsoon. J. Climate, 29, 8495-8514, https://doi.org/10.1175/ JCLI-D-16-0029.1.

Xie, P. and P. A. Arkin, 1997: Global precipitation: A 17-year monthly analysis based on gauge observations, satellite estimates, and numerical model outputs. Bull. Amer. Meteor. Soc., 78, 2539-2558, https://doi.org/10.1175/1520-0477(1997)078<2539: GPAYMA $>2.0 . C O ; 2$.

Xie, S.-P., K. Hu, J. Hafner, H. Tokinaga, Y. Du, G. Huang, and T. Sampe, 2009: Indian Ocean capacitor effect on Indo-western Pacific climate during the summer following El Niño. J. Climate, 22, 730-747, https://doi.org/10.1175/2008JCLI2544.1.

Xu, Z., K. Fan, and H. Wang, 2015: Decadal variation of summer precipitation over China and associated atmospheric circulation after the late 1990s. J. Climate, 28, 4086-4106, https:// doi.org/10.1175/JCLI-D-14-00464.1.

Yeh, S.-W., J.-S. Kug, B. Dewitte, M.-H. Kwon, B. Kirtman, and F.-F. Jin, 2009: El Niño in a changing climate. Nature, 461, 511-514, https://doi.org/10.1038/nature08316.

Zhang, R., A. Sumi, and M. Kimoto, 1996: Impact of El Niño on the East Asian monsoon: A diagnostic study of the '86/87 and ' $91 /$ 92 events. J. Meteor. Soc. Japan, 74, 49-62, https://doi.org/ 10.2151/jmsj1965.74.1_49.

Zhang, W., F.-F. Jin, J. X. Zhao, L. Qi, and H.-L. Ren, 2013: The possible influence of a non-conventional El Niño on the severe autumn drought of 2009 in southwest China. J. Climate, 26, 8392-8405, https://doi.org/10.1175/JCLI-D-12-00851.1. 
and A. G. Turner, 2014: Increasing autumn drought over southern China associated with ENSO regime shift. Geophys. Res. Lett., 41, 4020-4026, https://doi.org/10.1002/2014GL060130. , H. Li, M. F. Stuecker, F.-F. Jin, and A. G. Turner, 2016: A new understanding of El Niño's impact over East Asia: Dominance of the ENSO combination mode. J. Climate, 29, 4347-4359, https://doi.org/10.1175/JCLI-D-15-0104.1.

Zhang, Y., T. Li, and B. Wang, 2004: Decadal change of the spring snow depth over the Tibetan Plateau: The associated circulation and influence on the East Asian summer monsoon. J. Climate, 17, 2780-2793, https://doi.org/10.1175/1520-0442(2004)017<2780: DCOTSS $>2.0$.CO;2.

Zhao, Z., and G. Chen, 1995: The cause and forecast of long-term change of the latitudinal position of West Pacific subtropical high in early summer (in Chinese). J. Trop. Meteor., 11, 223-230.

Zhou, T., and Coauthors, 2009: Why the western Pacific subtropical high has extended westward since the late 1970s. J. Climate, 22, 2199-2215, https://doi.org/10.1175/2008JCLI2527.1. 